\title{
Efeito residual de lodo de curtume compostado sobre os teores de cromo e produtividade do milho verde
}

\author{
Residual effect of composted tannery sludge on chromium content and \\ yield of green corn
}

\author{
Wilon Pinheiro GUIMARAES ${ }^{1}$; Ademir Sergio Ferreira de ARAÚJO ${ }^{2^{\star}}$; Mara Lúcia Jacinto \\ OLIVEIRA ${ }^{2}$; Fábio Fernando de ARAÚJJO ${ }^{3}$; Wanderley José de MELO \\ ${ }^{1}$ Eng. Agr., Mestre, Laboratório de Qualidade do Solo, Universidade Federal do Piauí, Campus da Socopo, \\ Teresina, PI. E-mail: pinherim2009@gmail.com. Parte da Dissertação apresentada ao Programa de Pós- \\ Graduação em Agronomia, Universidade Federal do Piauí, Campus da Socopo, Teresina, PI. \\ ${ }^{2}$ Eng. Agr., Doutor, Laboratório de Qualidade do Solo, Universidade Federal do Piauí, Campus da Socopo, \\ Teresina, PI. E-mail: asfaruaj@yahoo.com.br, mjoliveira@yahoo.com.br \\ ${ }^{3}$ Eng. Agr., Doutor, Universidade do Oeste Paulista, UNOESTE, Rod. Raposo Tavares, Presidente Prudente, \\ SP.E-mail: fabio@unoeste.br \\ ${ }^{4}$ Eng. Agr., Doutor, Faculdade de Ciências Agrárias e Veterinárias, FCAV/UNESP, Jaboticabal, SP. E-mail: \\ wymelo@gmail.com \\ * Autor para correspondência (Corresponding author): Laboratório de Qualidade do Solo, Universidade Federal \\ do Piauí, Campus da Socopo, Teresina, PI. E-mail: asfaruaj@yahoo.com.br
}

Recebido em: 26-03-2014; Aceito em: 21-10-2014

\begin{abstract}
Resumo
A utilização do lodo de curtume compostado em sistemas agrícolas constitui uma alternativa para a reciclagem deste resíduo. No entanto, a presença de metais pesados, como o cromo $(\mathrm{Cr})$, representa fator de risco aos recursos ambientais. Neste trabalho, objetivou-se avaliar o efeito residual da aplicação do lodo de curtume compostado (LCC), após três aplicações anuais consecutivas, sobre a produtividade e acúmulo de $\mathrm{Cr}$ nas folhas e grãos de milho verde. As doses acumuladas foram $0,12,5,25$, 50 e $100 \mathrm{Mg} \mathrm{ha}^{-1}$ de LCC, base seca. O efeito residual do LCC influenciou positivamente o rendimento do milho verde, sendo que comprimento, diâmetro e número de espigas comerciais apresentaram resposta quadrática aos níveis de LCC acumulados nos três anos. Os teores de Cr nas folhas apresentaram ajuste linear significativo com as doses de LCC aplicadas. Não se detectaram diferenças significativas nos teores de $\mathrm{Cr}$ nos grãos.
\end{abstract}

Palavras-chave adicionais: compostagem; elementos-traço; metal pesado; resíduo industrial.

\begin{abstract}
The use of composted tannery sludge on agricultural systems constitutes an alternative for recycling this waste. However, the presence of metals, such as chromium (Cr), represents a risk for environmental resources. This study aimed to evaluate the residual effect of composted tannery sludge (CTS), after three annual consecutive applications, on yield and $\mathrm{Cr}$ accumulation in the leaves and grains of green corn. The applied accumulated doses were $0,12.5,25,50$ and $100 \mathrm{Mg} \mathrm{ha}^{1}$ dry weight basis. The residual effect of CTS positively influenced green corn yield and the length, diameter and number of commercial spikes showed a quadratic response to CTS application. The leaf $\mathrm{Cr}$ content showed a significant linear increase due to CTS but no significant differences were found for grain Cr content.
\end{abstract}

Additional keywords: composting; heavy metal; industrial waste; trace elements.

\section{Introdução}

A atividade curtumeira é parte importante da economia brasileira e movimenta, anualmente, 21 milhões de dólares (ARAÚJO et al., 2013). No entanto, a atividade é responsável pela geração de quantidades significativas de resíduos, sendo a maioria denominada lodo de curtume (LC), constituído principalmente por material orgânico e contendo diversos elementos químicos, com destaque maior para o cromo $(\mathrm{Cr})$ (CLAAS \& MAIA, 1994).
No Brasil, a principal indicação para disposição do lodo de curtume, preconizada pelos órgãos ambientais, tem sido o encaminhamento para aterros industriais. Esta disposição final do resíduo onera em muito as indústrias e contribui para riscos ambientais futuros por concentrar materiais tóxicos no solo.

Recentemente, o lodo de curtume vem sendo utilizado na agricultura, principalmente devido a sua composição química, que encerra consideráveis teores de matéria orgânica e de nutrientes das plantas. Contudo, se o resíduo 
apresenta potencial fertilizante, que pode contribuir para melhorar a fertilidade do solo e aumentar a produtividade das culturas (OLIVEIRA et al., 2002; KONRAD \& CASTILHOS, 2002; FERREIRA et al., 2003; ARAÚJO et al., 2008). Por outro lado, a aplicação do lodo de curtume no solo tem contribuído para elevação do $\mathrm{pH}$, da salinidade e dos teores de Cr (ARAÚJO et al., 2013).

Uma alternativa para utilização do lodo de curtume é o processo de compostagem, que pode contribuir para melhorar a qualidade do resíduo, promovendo redução no potencial de toxidez pela presença de elementos químicos e eliminação de patógenos (ARAÚJO \& MONTEIRO, 2006). O composto proveniente do lodo de curtume pode promover melhorias na qualidade do solo e na produtividade das plantas (SILVA et al., 2013). Entretanto, aplicações consecutivas de lodo curtume compostado podem gerar efeito residual no solo com reflexos na produtividade das culturas e na concentração de elementos químicos no solo, principalmente $\mathrm{Cr}$. O aumento da concentração deste metal no solo pode promover a absorção pela planta, acumulando-se nas folhas e nos grãos (SOUZA et al., 2005), o que constitui porta de entrada para a cadeia alimentar humana.

A hipótese do estudo é que aplicações sucessivas de lodo de curtume compostado promovem efeito residual cumulativo de elementos químicos que podem exercer efeitos positivos sobre a produtividade da planta, ou negativos, através do aumento da concentração de $\mathrm{Cr}$ no solo e, consequentemente, nas folhas e nos grãos.
Desta forma, o objetivo do trabalho foi avaliar o efeito residual de aplicações anuais sucessivas por três anos de lodo de curtume compostado sobre o rendimento em espigas de milho verde e o acúmulo de Cr no solo, nas folhas e nos grãos.

\section{Material e métodos}

O experimento com aplicação de lodo de curtume compostado (LCC) vem sendo realizado desde 2009 em campo experimental do Centro de Ciências Agrárias da Universidade Federal do Piauí, em Teresina, $\mathrm{PI}\left(05^{\circ} 02^{\prime}\right.$ latitude $\mathrm{S}$ e $42^{\circ} 47^{\prime}$ de longitude $\mathrm{W}, 52 \mathrm{~m}$ de altitude). O clima da região é do tipo $\mathrm{C} 1 \mathrm{sA}$ ', caracterizado como subúmido seco, megatérmico. As médias anuais de umidade relativa e precipitação pluvial são de $72,6 \%$ e $1.336 \mathrm{~mm}$, respectivamente, sendo que a maioria das precipitações ocorre nos meses de janeiro a abril (BASTOS \& ANDRADE JÚNIOR, 2008).

O lodo de curtume utilizado foi proveniente do curtume Europa, localizado no município de Teresina, Piauí. A formação da pilha de compostagem foi constituída por lodo de curtume misturado com bagaço de cana-de-açúcar e esterco bovino na proporção 1:1:3 (v:v:v). O processo de compostagem foi conduzido durante 85 dias, utilizando-se o método de pilhas revolvidas (USDA, 1980). Ao final do processo foram retiradas amostras em três pontos da pilha para avaliação das propriedades físico-químicas do LCC (Tabela 1).

Tabela 1 - Características químicas do lodo de curtume compostado (LCC) utilizado nos três anos de experimento e valores da concentração máxima permitida (CMP) pela legislação brasileira para uso de lodo de esgoto na agricultura.

\begin{tabular}{|c|c|c|c|c|}
\hline \multirow{2}{*}{ Propriedade } & \multicolumn{3}{|c|}{ LCC } & \multirow{2}{*}{$\mathrm{CMP}^{\mathrm{a}}$} \\
\hline & 2009 & 2010 & 2011 & \\
\hline $\mathrm{pH}$ & 7,8 & 7,2 & 7,5 & - \\
\hline $\mathrm{C}\left(\mathrm{g} \mathrm{kg}^{-1}\right)$ & 187,5 & 195,3 & 201,2 & - \\
\hline$N\left(\mathrm{~g} \mathrm{~kg}^{-1}\right)$ & 12,8 & 13,9 & 15,1 & - \\
\hline$P\left(g_{k g}^{-1}\right)$ & 4,02 & 3,83 & 4,91 & - \\
\hline$K\left(\mathrm{~g} \mathrm{~kg}^{-1}\right)$ & 3,25 & 3,51 & 2,90 & - \\
\hline $\mathrm{Ca}\left(\mathrm{g} \mathrm{kg}^{-1}\right)$ & 95,33 & 84,28 & 121,18 & - \\
\hline $\operatorname{Mg}\left(\mathrm{g} \mathrm{kg}^{-1}\right)$ & 6,80 & 5,71 & 7,21 & - \\
\hline$S\left(g ~ k g^{-1}\right)$ & 9,39 & 8,43 & 10,20 & - \\
\hline $\mathrm{Cu}\left(\mathrm{mg} \mathrm{kg}^{-1}\right)$ & 17,80 & 19,51 & 16,38 & 1500 \\
\hline $\mathrm{Zn}\left(\mathrm{mg} \mathrm{kg}^{-1}\right)$ & 141,67 & 128,31 & 127,81 & 2800 \\
\hline $\mathrm{Ni}\left(\mathrm{mg} \mathrm{kg}^{-1}\right)$ & 21,92 & 28,61 & 23,26 & 420 \\
\hline $\mathrm{Cd}\left(\mathrm{mg} \mathrm{kg}^{-1}\right)$ & 2,87 & 3,93 & 1,93 & 39 \\
\hline $\operatorname{Cr}\left(\mathrm{mg} \mathrm{kg}^{-1}\right)$ & 2255 & 2581 & 1943 & 1000 \\
\hline $\mathrm{Pb}\left(\mathrm{mg} \mathrm{kg}^{-1}\right)$ & 42,67 & 38,54 & 40,31 & 300 \\
\hline
\end{tabular}

${ }^{\mathrm{a}}$ (Brasil, 2006). 
O solo da área onde foi realizado o estudo é classificado como Neossolo Flúvico distrófico (EMBRAPA, 2006) com textura franco arenosa. As propriedades químicas do solo, após três anos de aplicação do LCC estão apresentadas na Tabela 2. As propriedades químicas do solo foram determinadas segundo metodologia descrita em TEDESCO et al. (1995). O pH foi determinado em água (relação solo:água 1:2,5) por potenciometria. $\mathrm{O} \mathrm{Ca}^{2+} \mathrm{e} \mathrm{Mg}^{2+}$ foram extraídos com solução de $\mathrm{KCl} 1 \mathrm{Mol} \mathrm{L}^{-1}$ e analisados por titrimetria com EDTA. O K ${ }^{+}$trocável e $\mathrm{P}$ disponível foram extraídos com o extrator Mehlich I e analisados por fotometria de chama e colorimetria, respectivamente. $\mathrm{O}$ teor de $\mathrm{Cr}$ foi determinado pelo método 3050b (USEPA, 1986).

Tabela 2 - Características químicas do solo após a aplicação por três anos consecutivos de lodo de curtume compostado (LCC).

\begin{tabular}{ccccccccccc}
\hline \multirow{2}{*}{ LCC $^{(1)}$} & \multicolumn{10}{c}{ Parâmetros } \\
\cline { 2 - 11 }$\left(\mathrm{Mg} \mathrm{ha}^{-1}\right)$ & $\mathrm{pH}$ & $\mathrm{MO}$ & $\mathrm{P}$ & $\mathrm{K}$ & $\mathrm{Ca}$ & $\mathrm{Mg}$ & $\mathrm{Cr}$ & $\mathrm{Cd}$ & $\mathrm{Ni}$ & $\mathrm{Pb}$ \\
\cline { 2 - 11 } & $\left(\mathrm{H}_{2} \mathrm{O}\right)$ & $\left(\mathrm{g} \mathrm{kg}^{-1}\right)$ & $\left(\mathrm{mg} \mathrm{dm}^{-3}\right)$ & $\left(\mathrm{cmol}_{\mathrm{c}} \mathrm{dm}^{-3}\right)$ & ---------- & $\left(\mathrm{mg} \mathrm{kg}^{-1}\right)$ & ----------- \\
\hline 0 & 6,6 & 11,8 & 2,97 & 46,8 & 1,19 & 0,36 & 3,73 & 0,06 & 0,66 & 1,94 \\
12,5 & 6,6 & 17,1 & 3,64 & 35,2 & 2,36 & 0,46 & 11,7 & 0,05 & 0,66 & 1,81 \\
25 & 7,1 & 18,4 & 4,17 & 31,3 & 3,45 & 0,32 & 16,7 & 0,07 & 0,73 & 1,94 \\
50 & 7,1 & 18,3 & 4,10 & 31,3 & 3,50 & 0,23 & 20,6 & 0,06 & 0,65 & 1,91 \\
100 & 7,5 & 18,1 & 3,04 & 19,5 & 4,56 & 0,17 & 32,7 & 0,06 & 0,62 & 2,15 \\
\hline
\end{tabular}

${ }^{(1)}$ Doses acumuladas de LCC em três anos.

Nos anos de 2009, 2010 e 2011, a área experimental foi cultivada com feijão-caupi (Vigna ungiculata), cultivar BR 17-Gurguéia. Durante estes anos o feijão-caupi foi totalmente colhido sem utilização de palhada para cobertura vegetal. A produtividade média obtida pelo feijão-caupi, nos últimos três anos, foi de $1.500 \mathrm{~kg} \mathrm{ha}^{-1}$. Nesta área, o LCC foi aplicado, em 2009 e 2010, nas doses de 0, 5, 10, 20 e $40 \mathrm{Mg} \mathrm{ha}^{-1}$. Em 2011, o LCC foi aplicado nas doses de 0, 2,5, 5, 10 e 20 $\mathrm{Mg} \mathrm{ha}^{-1}$. Desta forma, as taxas acumuladas de LCC, após três anos de aplicações anuais, foram de $0,12,5,25,50$ e $100 \mathrm{Mg} \mathrm{ha}^{-1}$. O LCC foi distribuído uniformemente nas parcelas (dimensões de $2 \times 5 \mathrm{~m}$ ) sendo, em seguida, incorporado ao solo com enxada a uma profundidade média de $20 \mathrm{~cm}$. O delineamento experimental adotado foi em blocos casualizados com quatro repetições.

Para avaliação do efeito residual das aplicações sucessivas do LCC, em novembro de 2011, efetivou-se cultivo de milho verde (híbrido duplo AG 1051, semi precoce) semeado nas mesmas parcelas e espaçados de $60 \mathrm{~cm}$ (entre linhas) e $30 \mathrm{~cm}$ (entre plantas), totalizando 60 plantas por parcela. A área útil foi constituída pelas duas fileiras centrais da parcela, desprezando-se as plantas contidas no espaço de $0,5 \mathrm{~m}$ no início e no fim das linhas úteis, totalizando 26 plantas por parcela útil. A irrigação foi realizada por aspersão convencional com turno de rega diário, aplicando-se uma lâmina d'água crescente de acordo com a exigência hídrica da cultura nos diferentes estágios fisiológicos, atingindo uma lâmina de $8 \mathrm{~mm}$ na fase de maior exigência da cultura.

As avaliações foram realizadas aos $52 \mathrm{e}$ 79 dias após a emergência (DAE). Aos 52 DAE, coletaram-se as folhas para avaliação dos teores de Cr. Foram colhidas cinco plantas, aleatoriamente dentro de área útil da parcela, das quais foi coletada a nona folha (VARGAS et al., 2012). Após a amostragem as folhas foram colocadas em saco de papel, submetidas à secagem em estufa com temperatura de $60{ }^{\circ} \mathrm{C}$ até massa constante, pesadas e moídas. Aos 79 DAE, coletaram-se espigas para avaliação do rendimento e dos teores de $\mathrm{Cr}$ nos grãos. Foram colhidas as espigas de dez plantas, obtidas aleatoriamente dentro de área útil de cada parcela. As espigas comerciais foram despalhadas e foi avaliado seu diâmetro (utilizando-se uma fita métrica). O rendimento de milho verde foi determinado através do número de espigas comerciais por hectare. Os grãos das espigas foram retirados, colocados para secar em estufa com temperatura de $60 \stackrel{\circ}{ } \mathrm{C}$ até a massa constante, pesados e moídos. Os teores de $\mathrm{Cr}$ nas folhas e grãos foram determinados através da metodologia proposta por USEPA (1986).

Os dados obtidos foram submetidos à análise de variância (ANOVA) pelo teste $\mathrm{F}$ e, 
quando este foi significativo a $5 \%$ de probabilidade, aplicou-se a análise de regressão. Os cálculos foram efetuados através do aplicativo estatístico SISVAR, versão 5.3 (FERREIRA et al., 2008).

\section{Resultados e discussão}

A composição química do LCC, utilizado durante os três anos, mostra relativa uniformidade nas variáveis químicas analisadas (Tabela 1). A relação $\mathrm{C} / \mathrm{N}$ do $\operatorname{LCC}(\leq 25)$ corresponde a um composto maturado (BRASIL, 2006). Os altos valores de $\mathrm{pH}$ e $\mathrm{Ca}$ no LCC estão relacionados aos hidroxidos e carbonatos utilizados no processo de curtimento (SELBACH et al., 1991). Os valores dos elementos-traço mostraram altos teores de $\mathrm{Cd}, \mathrm{Pb}, \mathrm{Cr}$ e Ni. Entretanto, exceto para o $\mathrm{Cr}$, os elementos-traço encontram-se abaixo dos limites máximos permitidos pela legislação brasileira para auso de lodo de esgoto na agricultura (BRASIL, 2006). Os teores de Cr foram aproximadamente duas vezes maiores que o limite máximo permitido pela legislação brasileira (Brasil, 2006). Entretanto, no solo os valores de

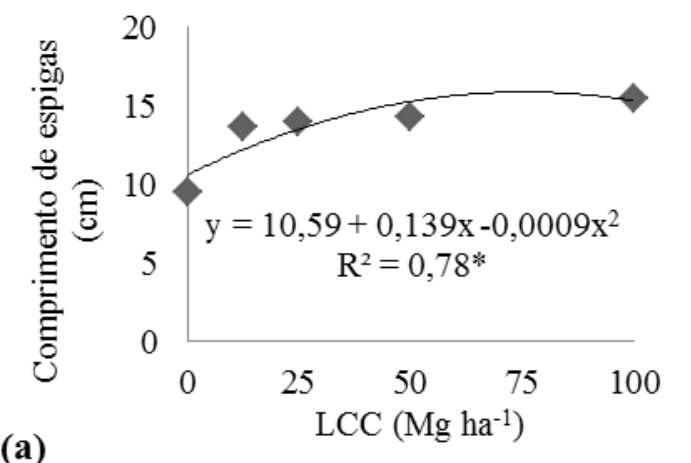

pH estão acima de 7,0 (Tabela 2) e, desta forma, o $\mathrm{Cr}$ encontra-se na forma trivalente $\left(\mathrm{Cr}^{3+}\right)$, mais estável (ALCÂNTARA \& CAMARGO, 2001), com baixa mobilidade (HAYES \& TRAINA, 1998) e menos tóxico, pois em valores de $\mathrm{pH}$ do solo acima de 5,0, o $\mathrm{Cr}$ encontra-se insolúvel na forma de $\mathrm{Cr}(\mathrm{OH})_{3}$ (AQUINO NETO \& CAMARGO, 2000). Os teores de $\mathrm{Cr}$ elevaram-se no solo, após a aplicação de LCC, entretanto os valores encontram-se abaixo do limite máximo permitido pela legislação brasileira para solos agrícolas que é de $150 \mathrm{mg} \mathrm{kg}^{-1}$ (BRASIL, 2006).

$O$ efeito residual de três aplicações anuais do LCC influenciou positivamente o crescimento da planta de milho verde. O comprimento e diâmetro das espigas apresentaram respostas quadráticas positivas aos níveis acumulados de LCC (Figura 1). O valor máximo estimado para o comprimento das espigas comerciais foi de $15,9 \mathrm{~cm}$, obtido com a dose acumulada de $77,2 \mathrm{Mg} \mathrm{ha}^{-1}$ de LCC. Para o diâmetro das espigas, o valor máximo estimado foi de $4,7 \mathrm{~cm}$, obtido com a dose de $74 \mathrm{Mg} \mathrm{ha}^{-1}$ de LCC.

(b)

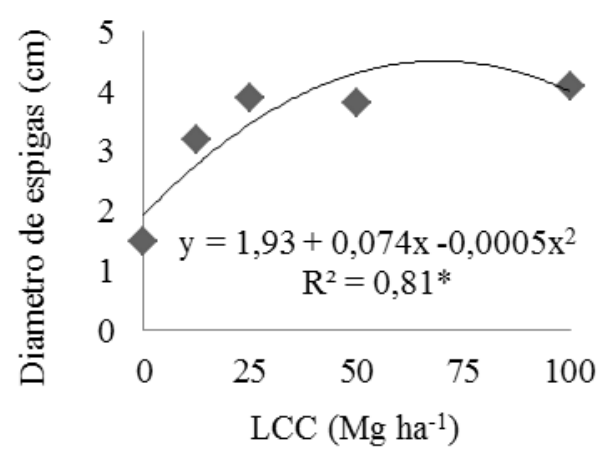

Figura 1 - Comprimento (a) e diâmetro (b) de espigas comerciais de milho verde despalhadas aos 79 dias após a emergência em cultivo após três anos de aplicações anuais de composto de lodo de curtume (LCC). *Significativo a $5 \%$ de probabilidade pelo teste $\mathrm{F}$.

Estes resultados indicam que a aplicação de LCC influenciou positivamente o tamanho das espigas comerciais, decorrente, provavelmente, da maior disponibilização de nutrientes no solo. A aplicação do LCC aumentou os teores de matéria orgânica e isto é de fundamental importância para a manutenção do potencial produtivo do solo (BARBOSA et al., 2007). Desta forma, a possibilidade de incrementar o teor de matéria orgânica, após a aplicação do LCC, apresenta efeito positivo nas propriedades químicas do solos e, consequentemente, na produtividade do milho-verde. Isto pode ocorrer devido ao aumento de cargas negativas além de enriquecer o solo com P e Ca (MELO et al., 1994; SILVA et al., 1998). O tamanho máximo de espiga, estimado com a dose de aproximadamente $75 \mathrm{Mg} \mathrm{ha}^{-1}$, é semelhante aos obtido por LIMA (2010) com a aplicação de $160 \mathrm{~kg} \mathrm{ha}^{-1}$ de N, condições em que o autor obteve comprimento de espiga de $15 \mathrm{~cm}$. $\mathrm{Na}$ avaliação do rendimento de espigas de milho verde, também se encontrou significância para o ajuste quadrático na resposta às doses de LCC aplicadas no período de três anos (Figura 2). O valor máximo estimado para o rendimento de espigas comerciais foi de 24.500 espigas ha ${ }^{-1}$, obtido com a dose acumulada de $106,5 \mathrm{Mg} \mathrm{ha}^{-1}$ de LCC.

Os resultados indicam que a aplicação sucessiva de LCC proporciona efeito residual no solo, o que pode, parcialmente, substituir a adubação química e manter o rendimento do milho verde em níveis satisfatórios. Embora não haja trabalhos que avaliem o efeito residual de lodo de curtume compostado, os resultados observados são semelhantes aos obtidos por 
SILVA et al. (2013), os quais, ao estudarem o efeito residual de doses de lodo de esgoto, verificaram que o resíduo apresentou efeito residual até o terceiro ano após a aplicação sobre o rendimento de grãos de milho.

Os teores de $\mathrm{Cr}$ nas folhas de milho verde apresentaram ajuste linear significativo e positivo com o aumento dos níveis de LCC aplicados no solo (Figura 2). De acordo com a equação de regressão, o valor máximo de Cr nas fo-
Ihas foi de $12,5 \mathrm{mg} \mathrm{kg}^{-1}$, obtido com a dose acumulada de $100 \mathrm{Mg} \mathrm{ha}^{-1}$ de LCC. Estes resultados indicam que houve absorção e acumulo de $\mathrm{Cr}$ nos tecidos foliares do milho, conforme reportado por SOUZA et al. (2005). Os valores observados encontram-se abaixo do limite máximo recomendado por KABATA-PENDIAS \& PENDIAS (1984), que é de $14 \mathrm{mg} \mathrm{kg}^{-1}$.

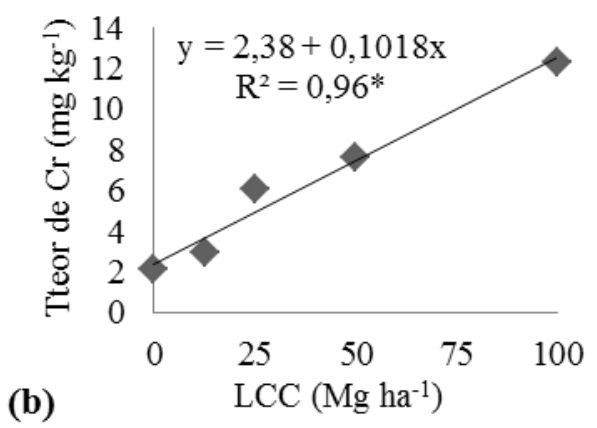

Figura 2 - Numero de espigas (a) e teor de Cr nas folhas (b) de milho verde aos 79 dias após a emergência em cultivo após três anos de aplicações anuais de composto de lodo de curtume. *Significativo a $5 \%$ de probabilidade, pelo teste $\mathrm{F}$.

Embora tenha promovido incremento significativo nos teores foliares de $\mathrm{Cr}$, não se detectaram diferenças significativas nos teores de $\mathrm{Cr}$ nos grãos de milho verde, sendo o valor médio obtido de $\mathrm{Cr}$ nos grãos de $0,35 \mathrm{mg} \mathrm{kg}^{-1}$. Isto indica que o $\mathrm{Cr}$ acumulado nas folhas não foi exportado proporcionalmente para os grãos e estes resultados são concordantes com MERLINO et al. (2010), que observaram, após onze anos de aplicação de lodo de esgoto na cultura do milho, que houve translocação parcial de $\mathrm{Cr}$ das folhas para os grãos de milho. Os valores de $\mathrm{Cr}$ encontrando nos grãos estão acima do permitido pela Agencia Nacional de Vigilância Sanitária (BRASIL, 1965) que é de $0,1 \mathrm{mg} \mathrm{kg}^{-1}$. Por outro lado, AWASHTHI (2000) e ARALAKSHMI \& GANESHAMURPTHY (2010) afirmam que o limite de $\mathrm{Cr}$ seguro nos alimentos é de $20 \mathrm{mg} \mathrm{kg}^{-1}$ de massa seca. Entretanto, a Organização Mundial de Saúde, através do CODEX alimentarius $n^{\circ}$. 193, não limita o teor de Cr nos alimentos, uma vez que este elemento é importante na alimentação humana e não apresenta importância para a saúde pública.

\section{Conclusões}

O efeito residual da disposição ao solo de lodo de curtume compostado, durante três anos consecutivos, proporciona aumento no comprimento, no diâmetro, no tamanho máximo e no rendimento das espigas de milho verde.

$\mathrm{O}$ Cr presente nas folhas do milho verde é apenas parcialmente exportado para os grãos do milho de modo que três aplicações anuais de lodo de curtume compostado não promoveram aumento significativo no teor do metal pesado nos grãos.

\section{Agradecimentos}

Ao CNPq e CAPES pelo auxílio financeiro à pesquisa de longa-duração com lodo de curtume compostado. Os autores agradecem ao CNPq pela concessão das bolsas de produtividade em pesquisas.

\section{Referências}

ARALAKSHMI, L. R.; GANESHAMURTHY, A. N. Heavy metal contamination of water bodies, soils and vegetables in peri-urban areas of Bangalore city of India. World Congress of Soil Science, Soil Solutions for a Changing World, Brisbane, v.37, p.1-6, 2010.

ARAÚJO, A. S. F.; SILVA, M. D. M.; LEITE, L. F. C.; ARAUJO, F. F.; DIAS, N. S. Soil pH, electric conductivity and organic matter after three years of consecutive applications of composted tannery sludge. African Journal of Agricultural Research, v.8, n.9, p.1204-1208, 2013.

ARAÚJO, A. S. F.; MONTEIRO, R. T. R. Microbial biomass and activity in a Brazilian soil plus untreated andcomposted textile sludge. Chemosphere, v.64, n.6, p.1043-1046, 2006. 
ARAÚJo, F. F.; TIRITAN, C. S.; PEREIRA, H. M.; JÚNIOR, O. C. Desenvolvimento do milho e fertilidade do solo após aplicação de lodo de curtume e fosforita. Revista Brasileira de Engenharia Agrícola e Ambiental, v.12, n.5, p.507-511, 2008.

AWASHTHI, S.K. Prevention of food adulteration act no 37 of 1954. Central and State Rules as Amended for 1999. Ashoka Law House: New Delhi, 2000.

BARBOSA, G. M. C.; TAVARES FILHO, J.; BRITO, O. R.; FONSECA, I. C. B. Efeito residual do lodo de esgoto na produtividade do milho safrinha. Revista Brasileira de Ciência do Solo, v.31, n.5, p.601-605, 2007.

BASTOS, E. A.; ANDRADE JÚNIOR, A. S. Boletim agrometeorológico do ano de 2008 para o município de Teresina, PI. Teresina: Embrapa Meio-Norte, 2008. 37p. (Documentos, 181).

BRASIL. Agência Nacional de Vigilância Sanitária. Legislação em vigilância sanitária: decreto no 55.871 de 26 de março de 1965. Disponível em: <http://portal.anvisa.gov.br>. Acesso em 20 outubro. 2013.

BRASIL. Ministério do Meio Ambiente. Resolução CONAMA n. 375, de 29 de agosto de 2006. Define critérios e procedimentos, para o uso agrícola de lodos de esgoto gerado em estação de tratamento de esgoto sanitário e seus produtos derivados, e dá outras providências. Diário Oficial da União, Brasília, 29 ago. 2006.

CLAAS, I.C.; MAIA, R.A.M. Manual básico de resíduos industriais de curtume. Porto Alegre: SENAI, 1994. 22p.

FERREIRA, A. S.; CAMARGO, F. A. O; TEDESCO, M. J.;. BISSANI, C. A. Alterações de atributos químicos e biológicos de solo e rendimento de milho e soja pela utilização de resíduos de curtume e carbonífero. Revista Brasileira de Ciência do Solo, v.27, n.4, p.755-763, 2003.

FERREIRA, D. F. ADRIANO, D. M.; HUANG, P. M.; LOGAN, T. I.; CHECKAI, R. T.; BAILEY, G. W. SISVAR: um programa para análises e ensino de estatística. Revista Symposium, v. 6, n.1, p. 36-41, 2008.

HAYES, K. F.; TRAINA, S. J. Metal ion speciation and its significance in ecosystem health. In: soil chemistry and ecosystems health. (Special Publication, 52). Madison: SSSA, 1998.

KABATA-PENDIAS, A.; PENDIAS, $H$. Trace elements in soils and plants. Florida: CRC Press, 1984. 315p.

KONRAD, E. E.; CASTILHOS, D. D. Alterações químicas do solo e crescimento do milho decorrentes da adição de lodos de curtume. Revista Brasileira de Ciência do Solo, Viçosa, v.26, n.1, p.257-265, 2002.
MELO, W. J.; MARQUES, M. O.; SANTIAGO, G. Efeito das doses crescentes de lodo de esgoto sobre frações da matéria orgânica e CTC de um Latossolo cultivado com cana-de-açúcar. Revista Brasileira de Ciência do Solo,Viçosa, v.18, n.3, p.449-455, 1994.

MERLINO, L. C. S.; MELO, W. J.; MACEDO, F. G.; GUEDES, A. C. T. P.; RIBEIRO, M. H.; MELO, V. P.; MELO, G. M. P. Bário, cádmio, cromo e chumbo em plantas de milho e em latossolo após onze aplicações anuais de lodo de esgoto. Revista Brasileira de Ciência do Solo, v.34, n.12, p.2031-2039, 2010.

OLIVEIRA, F. C.; MATIAZZO, M. E.; MARCIANO, C. R.; ROSSETO, R. Efeitos de aplicações sucessivas de lodo de esgoto em Latossolo Amarelo distrófico cultivado com cana-de-açúcar: carbono orgânico, condutividade elétrica, $\mathrm{pH}$ e CTC. Revista Brasileira de Ciência do Solo,v.26, n.3, p.505-519, 2002.

SELBACH, P. A.; TEDESCO, M. J.; GIANELLO, C.; CAVALLET, L. E. Disposal and biodegradation of tannery sludge in soil. Revista do Couro, Estância Velha, v.4, n.1, p.51-62, 1991.

SILVA, F. C.; BOARETTO, A. E.; BERTON, R. S.; ZOTELLI, H. B.; PEXE, C. A.; MENDONÇA, E. Cana-de-açúcar cultivada em solo adubado com lodo de esgoto. Pesquisa Agropecuária Brasileira, Brasília, v.33, n.1, p.1-8, 1998.

SILVA, M. D. M.; ARAÚJO, A. S. F.; NUNES, L. A. P. L.; MELO, W. J.; SINGH, R. P. Heavy metals in cowpea (Vigna unguiculata L.) after tannery sludge compost amendemt. Chilean Journal of Agricultural Research, Chillan, v.73, n.5, p.282-287, 2013.

SOUZA, E. R. B.; BORGES, J. D.; LEANDRO, W. M.; OLIVEIRA JÚNIOR, J. P.; OLIVEIRA, I. P.; XIMENES, P. A.; CARNEIRO, M. F.; BARROS, R.. Teores de metais tóxicos nas folhas de plantas de milho fertilizadas com lodo de curtume. Pesquisa Agropecuária Tropical, Goiânia, v.35, n.2, p.117-122, 2005.

TEDESCO, M. J.; GIANELLO, C.; BISSANI, C. A. Analises de solos, plantas e outros materiais. Porto Alegre: UFRGS, 1995.

USDA. United States Department of Agriculture .Manual for composting of sewage sludge by the beltsville aerated-pile method. Washington, 1980. 65p.

USEPA. United States Environmental Protection Agency. Test method for evaluating solid wastes. Washington, 1986. 152p.

VARGAS, V. P.; SANGOI, L.; ERNANI, P. R.; SIEGA, E.; CARNIEL, G.; FERREIRA, M. A. Os atributos nas folhas são mais eficientes que o $\mathrm{N}$ mineral no solo para avaliar a disponibilidade desse nutriente para 0 milho. Bragantia, Campinas, v.71, n.2, p.245-255, 2012. 